\title{
Application of multivariate analysis of NMR spectra of poly( $N$-isopropylacrylamide) to assignment of stereostructures and prediction of tacticity distribution
}

\author{
Tomohiro Hirano $^{1}$, Takuya Anmoto ${ }^{1}$, Nao Umezawa ${ }^{1}$, Hikaru Momose ${ }^{1,2}$, Yukiteru Katsumoto ${ }^{3}$, \\ Miyuki Oshimura $^{1}$ and Koichi Ute ${ }^{1}$
}

In this paper, we report multivariate analyses, such as principal component analysis and partial least-squares regression, of NMR spectra of poly( $N$-isopropylacrylamide)s [poly(NIPAAm)s]. Principal component analysis successfully interpreted the assignments of NMR spectra of poly(NIPAAm)s in terms of stereostructures for the methine carbons at triad levels and for the methylene protons at tetrad levels. Furthermore, triad tacticity was successfully predicted by partial least-squares regression of ${ }^{1} \mathrm{H}$ NMR spectra of the methine and methylene groups, although the low resolution of the signals of the methine protons confines determination of tacticities by conventional methods to the diad levels. Consequently, it is assumed that chemometric approaches are useful for assigning NMR spectra in terms of stereostructures and for predicting tacticity distributions.

Polymer Journal (2012) 44, 815-820; doi:10.1038/pj.2012.61; published online 18 April 2012

Keywords: chemometrics; NMR; partial least-squares regression; poly( $N$-isopropylacrylamide); principal component analysis; stereostructures

\section{INTRODUCTION}

NMR spectroscopy is a powerful tool for analyzing the primary structures of polymers. ${ }^{1-3}$ In particular, stereostructures have been extensively studied using NMR spectroscopies, ${ }^{4}$ since the first reports on the triad tacticities of poly(methyl methacrylate)s, determined by ${ }^{1} \mathrm{H}$ NMR in $1960 .^{5-7}$

Recently, we reported stereospecific radical polymerizations of $\mathrm{N}$-isopropylacrylamide (NIPAAm), at low temperatures, in polar solvents or in non-polar solvents, in the presence of alcohols. ${ }^{8-11}$ The diad tacticities were easily determined from the ${ }^{1} \mathrm{H}$ NMR signals of the methylene groups in the main chain; the signals showed typical splitting as a result of diad stereostructures, as measured in deuterated dimethyl sulfoxide (DMSO- $d_{6}$ ) at $150{ }^{\circ} \mathrm{C} .{ }^{12-15}$ However, assignments, in terms of triad stereostructures, had not previously been made. We therefore assigned the ${ }^{13} \mathrm{C}$ NMR signals of the methine carbons in the main chain, at triad levels, by comparing the NMR spectra of poly(NIPAAm)s with a wide range of stereoregularities, such as isotactic, syndiotactic and heterotactic polymers, reported previously. ${ }^{10,16}$ The measurement conditions were optimized by mixing DMSO- $d_{6}$ with both $\mathrm{D}_{2} \mathrm{O}$ and 2,2,3,3,4,4,5,5-octafluoro1-pentanol $\left(\mathrm{PenOH}-\mathrm{F}_{8}\right)$ at $100{ }^{\circ} \mathrm{C}$.

Multivariate analysis is a powerful tool that can transform complex information into more useful sets of information, and that can extract vital differences from data that may look similar by other methods. Multivariate analysis has been applied to spectroscopic analysis of polymers to extract information about primary structures, which is buried in broad and/or complicated spectra. ${ }^{17-23}$ For example, principal component analysis (PCA) of ${ }^{13} \mathrm{C}$ NMR spectra of copolymers of methyl methacrylate and tert-butyl methacrylate, with various chemical compositions, the homopolymers of the two methacrylates, and blends of the homopolymers with various blend ratios extracted separately information of chemical composition and that of comonomer sequence. ${ }^{23}$ Furthermore, chemical composition of the copolymers was successfully predicted by partial least-squares (PLS) regression of ${ }^{13} \mathrm{C}$ NMR spectra of the homopolymers of the two methacrylates, and the blends of the homopolymers. ${ }^{23}$

Measurements of the ${ }^{13} \mathrm{C}$ NMR spectra of poly(NIPAAm)s to determine the triad tacticities require a large amount of sample, a long time, and use of a mixed solvent (DMSO- $d_{6}: \mathrm{D}_{2} \mathrm{O}: \mathrm{PenOH}-$ $\left.\mathrm{F}_{8}=75: 10: 15 \mathrm{wt} \%\right)$. If the triad tacticities are determined from ${ }^{1} \mathrm{H}$ NMR spectra, a single solvent (DMSO- $d_{6}$ ) can be used and both sample and time can be saved. The objectives of this work are twofold: (1) to investigate whether assignments of NMR spectra in terms of stereostructures can be interpreted by PCA, and (2) to examine whether triad tacticities can be predicted by PLS regression of ${ }^{1} \mathrm{H}$ NMR spectra, from which only diad tacticity can be determined.

${ }^{1}$ Department of Chemical Science and Technology, Institute of Technology and Science, The University of Tokushima, Tokushima, Japan; ${ }^{2}$ Corporate Research Laboratories, Mitsubishi Rayon Co., Ltd, Otake, Hiroshima, Japan and ${ }^{3}$ Graduate School of Science, Hiroshima University, Higashi-Hiroshima, Hiroshima, Japan

Correspondence: Dr T Hirano, Department of Chemical Science and Technology, Institute of Technology and Science, The University of Tokushima, 2-1 Minamijosanjima, Tokushima 770-8506, Japan.

E-mail: hirano@chem.tokushima-u.ac.jp

Received 26 January 2012; revised 14 February 2012; accepted 23 February 2012; published online 18 April 2012 


\section{EXPERIMENTAL PROCEDURE}

\section{Materials}

Poly(NIPAAm)s with a wide range of stereoregularities were prepared under the conditions reported in the literature. ${ }^{8-11}$ Only the initiating system was changed, from $n$ - $\mathrm{Bu}_{3} \mathrm{~B}$ under air to dimethyl 2,2' -azobisisobutyrate (supplied by Otsuka Chemical Co., Ltd, Osaka, Japan) under UV irradiation with a UV-LED lamp (375 nm, Optocode Co., Tokyo, Japan) at a distance of ca. $5 \mathrm{~cm}$ from the polymerization mixture.

\section{Measurements}

The molecular weights and molecular-weight distributions of the polymers were determined by size-exclusion chromatography (SEC); the chromatograph was calibrated using standard polystyrene samples. Size-exclusion chromatography was performed with an HLC 8220 chromatograph (Tosoh Corp., Tokyo, Japan) equipped with TSK-gel columns (SuperHM-M and SuperHM-H, both $6.5-\mathrm{mm}$ inner diameter $\times 150-\mathrm{mm}$ long; Tosoh Corp.). Dimethylformamide containing $\mathrm{LiBr}\left(10 \mathrm{mmoll}^{-1}\right)$ was used as the eluent at $40^{\circ} \mathrm{C}$ with a flow rate of $0.35 \mathrm{ml} \mathrm{min}^{-1}$. The polymer concentration was $1.0 \mathrm{mg} \mathrm{ml}^{-1}$.

\section{NMR measurements of poly(NIPAAm)s}

${ }^{1} \mathrm{H}$ NMR spectra $(400 \mathrm{MHz})$ were measured using an EX-400 spectrometer (JEOL Ltd, Tokyo, Japan), equipped with a 5-mm multinuclear direct detection probe $\left(45^{\circ}\right.$ pulse $(6.0 \mu \mathrm{s})$, pulse repetition $\left.=10.0 \mathrm{~s}, 16 \mathrm{scans}\right)$, in DMSO- $d_{6}(4 \mathrm{wt} / \mathrm{vol} \%)$ at $150{ }^{\circ} \mathrm{C} .{ }^{13} \mathrm{C}$ NMR spectra $(100 \mathrm{MHz})$ were measured using an ECX400 spectrometer (JEOL Ltd), equipped with a 10-mm multinuclear direct detection probe $\left(45^{\circ}\right.$ pulse $(7.75 \mu \mathrm{s})$, pulse repetition $=2.73 \mathrm{~s}$, 5000 scans, with ${ }^{1} \mathrm{H}$-broadband decoupling), in a mixed solvent (DMSO$d_{6}: \mathrm{D}_{2} \mathrm{O}:$ PenOH-F$\left.=75: 10: 15 \mathrm{wt} \%\right)(8 \mathrm{wt} / \mathrm{vol} \%)$ at $100^{\circ} \mathrm{C}$.

The ${ }^{1} \mathrm{H}$ and ${ }^{13} \mathrm{C}$ NMR data were zero-filled twice and multiplied by exponential functions with line-broadening factors of 0.5 and $3.0 \mathrm{~Hz}$, respectively, before Fourier transformation. Proton chemical shifts were referenced to internal TMS ( $\delta=0.00$ p.p.m.). Carbon chemical shifts were referenced to $\mathrm{PenOH}-\mathrm{F}_{8}\left(\mathrm{HCF}_{2} \mathrm{CF}_{2} \mathrm{CF}_{2} \mathrm{CF}_{2}-\mathrm{CH}_{2}-\mathrm{OH}\right.$ : $\delta=59.06$ p.p.m. $)$

\section{PCA of NMR signals of the methine carbons and methylene} protons in main chain

Multivariate analysis was conducted using Sirius ver.7.0 (Pattern Recognition Systems, Bergen, Norway). The data matrix used for PCA analysis was composed from the spectra of eight samples, summarized in Table 1. A composite of ${ }^{1} \mathrm{H}$ NMR (the methylene proton region; 1.18-1.80 p.p.m.) and

${ }^{13} \mathrm{C}$ NMR (the methine carbon region; 41.04-43.24 p.p.m.) spectra was used as the spectral vector in the matrix. The composition was carried out as follows. First, bucket integration was applied to each spectrum to reduce the matrix size for PCA. The bucket integration was performed with Alice2 ver.5 for metabolome ver.1.6 (JEOL Ltd). The integration intervals of the ${ }^{1} \mathrm{H}$ and ${ }^{13} \mathrm{C}$ NMR spectra were 0.02 p.p.m. and 0.05 p.p.m., respectively. The sum of the integral intensities in each region was normalized to 100 , and, then, these normalized ${ }^{1} \mathrm{H}$ and ${ }^{13} \mathrm{C}$ NMR spectra were simply combined to one spectral vector. The eight spectral vectors obtained after the pretreatment were meancentered and used for the PCA procedure. The NIPALS algorithm was used for the PCA calculations.

\section{PLS regression of NMR signals of the methine and methylene} protons in main chain

Eight ${ }^{1} \mathrm{H}$ NMR spectra in the methine and methylene protons region (1.18-2.24 p.p.m.) were used as a training set for the calibration. Bucket integration with an interval of 0.0025 p.p.m., normalization, and meancentering were performed. The triad tacticities were determined from the ${ }^{13} \mathrm{C}$ NMR signals of the methine carbons. The data were subjected to leaveone-out cross validations, followed by PLS- 1 analysis.

\section{RESULTS AND DISCUSSION}

\section{Preparation of poly(NIPAAm)s with a wide range} of stereoregularities

Radical polymerization of NIPAAm was carried out at low temperatures in the absence or presence of alcohols (Table 1). The contents of the racemo $(r)$ diad were determined from the ${ }^{1} \mathrm{H}$ NMR signals of the methine groups in the main chain, and one of the signals of the in-chain methylene groups with the meso $(m)$ configuration, observed at a lower magnetic field, in DMSO- $d_{6}$ at $150^{\circ} \mathrm{C}$ (Figure 1). This is because the signals of the in-chain methylene groups with the $r$ configuration overlapped slightly with one of the signals of the inchain methylene groups with the $m$ configuration, observed at a higher magnetic field, which also overlapped with the ${ }^{13} \mathrm{C}$-satellite peak of $\left(\mathrm{CH}_{3}\right)_{2} \mathrm{CH}$. The triad tacticities were determined from the ${ }^{13} \mathrm{C}$ NMR signals of the methine groups in the main chain, in a mixed solvent (DMSO- $d_{6}: \mathrm{D}_{2} \mathrm{O}: \mathrm{PenOH}-\mathrm{F}_{8}=75: 10: 15 \mathrm{wt} \%$ ) at $100{ }^{\circ} \mathrm{C} .{ }^{10}$ The contents of the $r$ diad, calculated from $r=r r+m r / 2$, agreed well with those determined using ${ }^{1} \mathrm{H}$ NMR spectra. This means that the triad tacticities determined using ${ }^{13} \mathrm{C}$ NMR spectra are sufficiently accurate, and that polymers rich in isotactic (runs 1 and 2), syndiotactic (runs

Table 1 Radical polymerization of NIPAAm at low temperatures for $24 \mathrm{~h}^{\mathrm{a}}$

\begin{tabular}{|c|c|c|c|c|c|c|c|c|c|c|c|}
\hline \multirow[b]{2}{*}{ Run } & \multirow[b]{2}{*}{ Solvent } & \multirow[b]{2}{*}{ Additive } & \multirow[b]{2}{*}{ Temp $\left({ }^{\circ} \mathrm{C}\right)$} & \multirow[b]{2}{*}{ Yield (\%) } & \multirow[b]{2}{*}{$r \operatorname{Diad}^{\mathrm{b}}(\%)$} & \multicolumn{3}{|c|}{ Triad tacticity $(\%)^{c}$} & \multirow[b]{2}{*}{ r Diad ${ }^{\mathrm{d}}(\%)$} & \multirow[b]{2}{*}{$M_{\mathrm{n}}^{\mathrm{e}} \times 10^{-4}$} & \multirow[b]{2}{*}{$M_{\mathrm{w}} \mathrm{e} / M_{\mathrm{n}}$} \\
\hline & & & & & & $m m$ & $m r$ & $r r$ & & & \\
\hline 1 & DMF & None & -40 & 94 & 36.5 & 50.2 & 28.2 & 21.5 & 35.7 & 1.5 & 1.7 \\
\hline 2 & $\mathrm{CH}_{3} \mathrm{CN}$ & None & -20 & 94 & 47.0 & 33.5 & 41.6 & 24.9 & 45.7 & 3.9 & 4.4 \\
\hline 3 & $\mathrm{MeOH}$ & None & 0 & 68 & 55.0 & 18.7 & 53.6 & 27.7 & 54.5 & 9.6 & 3.2 \\
\hline 4 & Toluene & $\mathrm{MeOH}$ & -40 & 87 & 60.5 & 13.2 & 54.1 & 32.7 & 59.8 & 6.5 & 2.5 \\
\hline 5 & Toluene & $t \mathrm{BuOH}$ & -40 & 92 & 65.8 & 14.2 & 43.1 & 42.7 & 64.3 & 7.5 & 2.9 \\
\hline 6 & Toluene & $3 \mathrm{Me} 3 \mathrm{PenOH}{ }^{f}$ & -60 & 79 & 68.4 & 8.9 & 46.3 & 44.8 & 68.0 & 7.1 & 1.9 \\
\hline 7 & Toluene & HFIPg & -60 & 75 & 49.3 & 24.9 & 55.7 & 19.4 & 47.3 & 12.9 & 2.4 \\
\hline 8 & Toluene & NFTB $^{h}$ & -40 & 30 & 55.0 & 8.7 & 74.0 & 17.3 & 54.3 & 2.9 & 1.7 \\
\hline
\end{tabular}




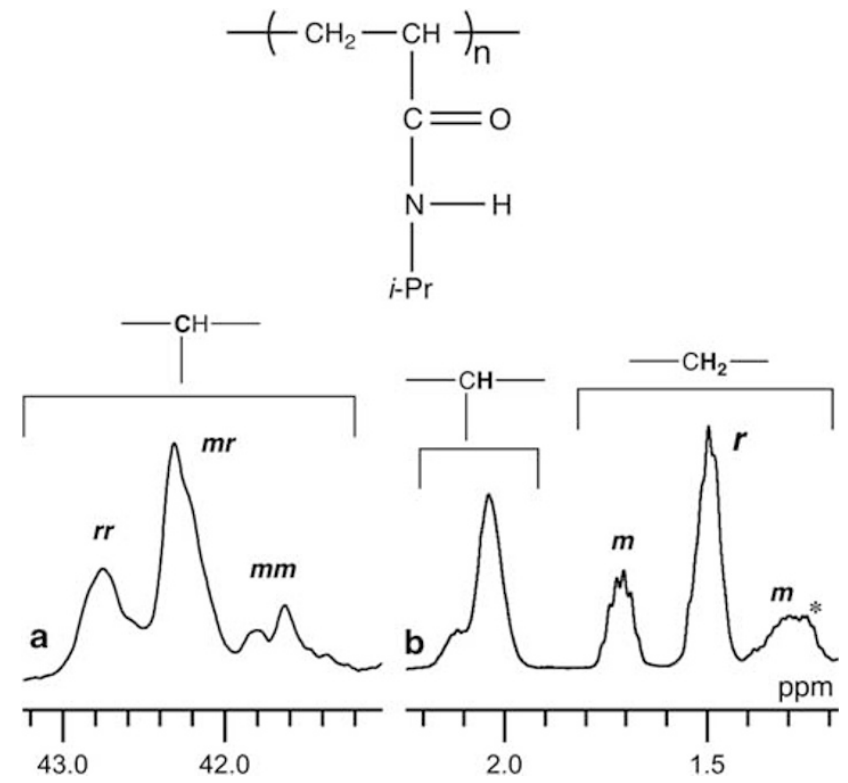

Figure 1 (a) ${ }^{13} \mathrm{C}$ NMR spectrum of the methine carbons of poly(NIPAAm) (Table 1 , run 3 ), measured in DMSO- $d_{6}: \mathrm{D}_{2} \mathrm{O}: \mathrm{PenOH}-\mathrm{F}_{8}=75: 10: 15 \mathrm{wt} \%$ at $100{ }^{\circ} \mathrm{C}$ and (b) ${ }^{1} \mathrm{H}$ NMR spectrum of the methine and methylene protons of poly(NIPAAm), measured in DMSO- $d_{6}$ at $150^{\circ} \mathrm{C}$. The asterisk indicates the ${ }^{13} \mathrm{C}$ satellite peak from the $\left(\mathrm{CH}_{3}\right)_{2} \mathrm{CH}$ - groups.

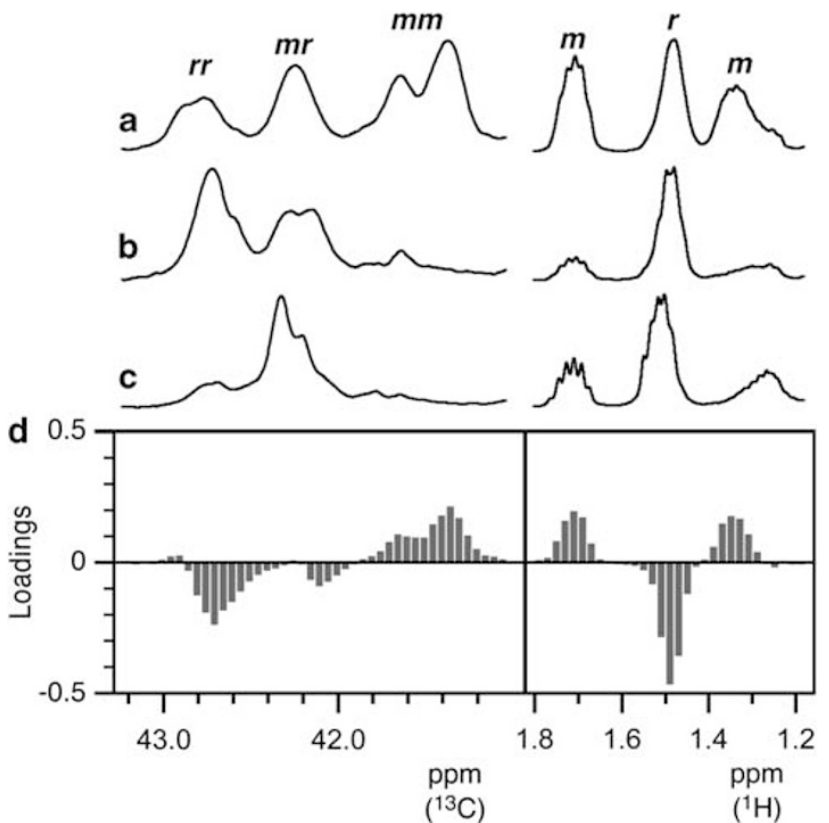

Figure 2 NMR spectra of the methine carbons and methylene protons of poly(NIPAAm)s rich in (a) isotactic (Table 1, run 1), (b) syndiotactic (Table 1, run 6), and (c) heterotactic stereosequences (Table 1, run 8) and (d) PC1 loadings plots.

3-6) and heterotactic (runs 7 and 8) stereosequences were successfully obtained.

\section{Application of PCA to assignment of NMR signals in terms of stereostructures}

Figures $2 \mathrm{a}-\mathrm{c}$ show ${ }^{13} \mathrm{C}$ NMR spectra of the main-chain methine carbons and ${ }^{1} \mathrm{H}$ NMR spectra of the main-chain methylene protons of

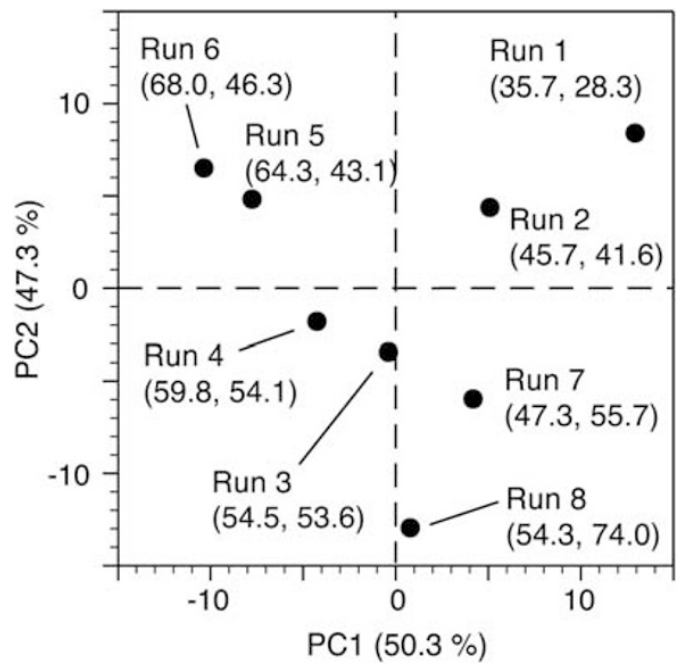

Figure 3 PC1-PC2 score plots for ${ }^{13} \mathrm{C}$ NMR spectra of the main-chain methine carbons and ${ }^{1} \mathrm{H}$ NMR spectra of the main-chain methylene protons of poly(NIPAAm)s. The values in parentheses are $r$ diad content and $m r$ triad content, respectively: $(r, m r)$.

representative poly(NIPAAm)s rich in (a) isotactic, (b) syndiotactic and $(c)$ heterotactic stereosequences. PCA was performed on the data set for these spectral regions of eight samples. The contribution rates for the first principal component (PC1) and second principal component (PC2) were $50.3 \%$ and $47.3 \%$, respectively. The first two principal component factors accounted for $97.6 \%$ of the spectral information of the data set.

Figure $2 \mathrm{~d}$ shows the PC1 loadings plots. The PCA loadings are the eigenvectors of the cross-product matrix of the spectral space. They therefore contain information on the spectral variations of the original data set. Positive PC1 loadings were observed around the signals of the methylene protons in the main chain with the $m$ configuration, and around the methine carbon signals from the $\mathrm{mm}$ configuration. In contrast, the PC1 loadings had negative values near the methylene proton signals from the $r$ configuration and near the methine carbon signals from the $r r$ configuration. (Note: The negative PC1 loadings were also observed at the signal of the methine carbons with the $m r$ configuration (Figure 2d). Taking into account that no clear PC2 loadings were observed in the corresponding region (Figure $4 \mathrm{~d}$ ), the peak was assigned to the $r m r r$ pentad, as shown in Figure 4c.) Figure 3 depicts the Karhanen-Loève plots for the $\mathrm{PC} 1$ and $\mathrm{PC} 2$ scores. It was found that the PC1 score correlates well with the $r$ diad contents of the sample. Consequently, the PC1 loadings are related to changes in the diad stereostructures ( $m$ and $r$ configurations).

Figure 4d shows the PC2 loadings plots. For the methylene proton region, each peaks can be divided into at least two components, suggesting that the methylene proton signals are split as a result of at least tetrad stereosequences. In fact, a lower-field shoulder peak was observed in the signals of the methylene protons with the $r$ configuration only when the polymers were rich in heterotactic stereosequences. The shoulder peak was therefore assigned to an $\mathrm{mrm}$ tetrad, as shown in Figure 4c. Negative PC2 loadings were observed at the shoulder peak in the signals of the methylene protons with the $r$ configuration and at the signals of the methine carbons with the $m r$ configuration. These results suggested that the PC2 loadings were related to changes in the triad stereostructures, in particular the $m r$ configuration. The PC1-PC2 score plots also 


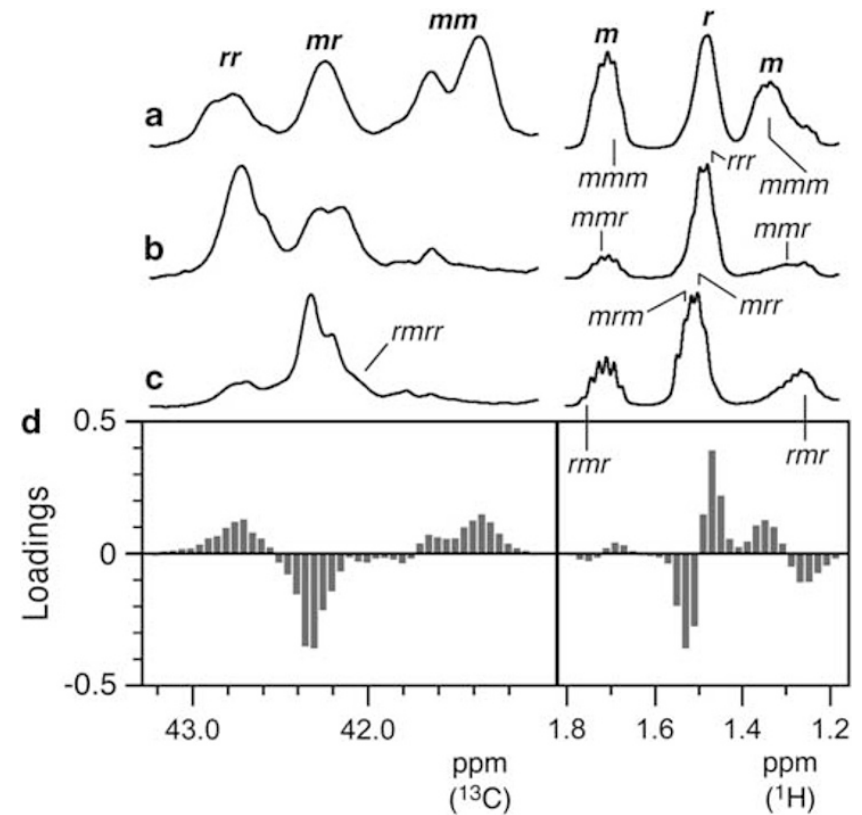

Figure 4 NMR spectra of the methine carbons and methylene protons of poly(NIPAAm)s rich in (a) isotactic (Table 1, run 1), (b) syndiotactic (Table 1, run 6) and (c) heterotactic stereosequences (Table 1, run 8 ) and (d) PC2 loadings plots.

showed that the PC2 score tended to decrease with increasing $m r$-triad content (Figure 3). Furthermore, negative loadings were observed at the signals of the methylene protons with the $m$ configuration (see Figure $4 \mathrm{~d}$ ). These peaks were therefore assigned to an $r m r$ tetrad, as shown in Figure $4 \mathrm{c}$.

Positive PC2 loadings were observed at the signals of the methine carbons with the $\mathrm{mm}$ and $\mathrm{rr}$ configurations (see Figure $4 \mathrm{~d}$ ). The signals of the methylene protons, at which positive PC2 loadings were observed, were therefore assigned to $\mathrm{mmm}$ and $\mathrm{rrr}$ tetrads, as shown in Figures $4 \mathrm{a}$ and $\mathrm{b}$, respectively. The signals of the methylene protons, at which PC2 loadings were scarcely observed, were therefore assigned to $m m r$ and $m r r$ tetrad, as shown in Figures $4 \mathrm{~b}$ and c, because these stereosequences include both $m r$ triad and $m m$ or $r r$ triad. Consequently, the assignments of the NMR spectra of poly(NIPAAm)s, in terms of stereostructures, were successfully interpreted by PCA loadings. Furthermore, assignments at the tetrad levels were also achieved for the signals of the methylene protons.

\section{Application of PLS regression to prediction of triad tacticities}

The ${ }^{1} \mathrm{H}$ NMR signals from the methine protons in the main chains of poly(NIPAAm)s contain information on triad tacticities. However, the low resolution confines determination of tacticities from the signals of the methine and methylene protons to the diad levels (see Figure 1). PLS regression was therefore applied to the data set obtained by bucket integration of the ${ }^{1} \mathrm{H}$ NMR signals of the methine and methylene protons of poly(NIPAAm)s. For calibration, the triad tacticities of each sample, separately determined from the ${ }^{13} \mathrm{C}$ NMR spectra of the methine carbons, were used.

Leave-one-out cross-validations of the $\mathrm{mm}, \mathrm{mr}$ and $\mathrm{rr}$ triads were conducted. Figure 5 shows the PLS models with two latent variables (LV). The first two LVs accounted for $95.8 \%$ of the data set, regardless of the stereosequences $(\mathrm{mm}: \mathrm{LV} 1=55.4 \%, \mathrm{LV} 2=40.4 \%$; $m r$ : $\mathrm{LV} 1=44.1 \%, \mathrm{LV} 2=51.7 \% ; r r: \mathrm{LV} 1=52.3 \%, \mathrm{LV} 2=43.5 \%)$. The high
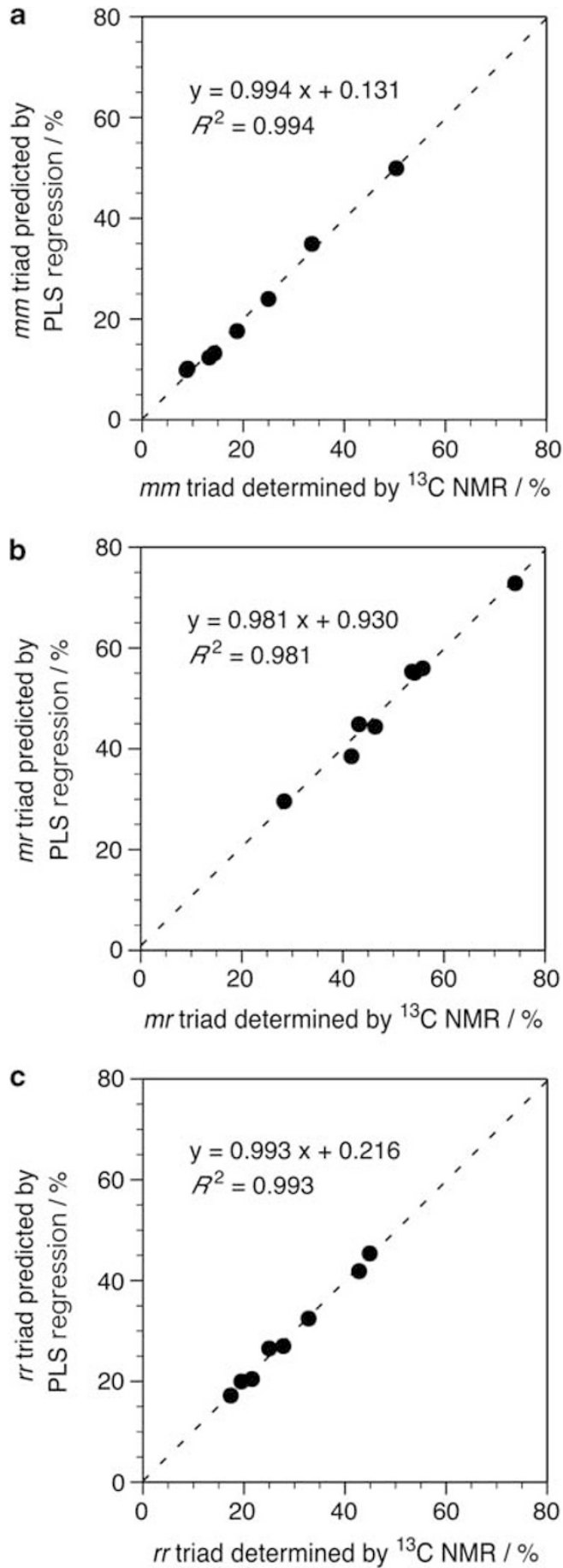

Figure 5 Correlation of triad tacticities predicted by leave-one-out test with those determined by ${ }^{13} \mathrm{C}$ NMR: (a) $\mathrm{mm}$, (b) $\mathrm{mr}$ and (c) $r r$ triads.

$R^{2}$ values suggested successful prediction of triad tacticities, using these models.

We prepared a test sample by mixing poly(NIPAAm) rich in isotactic stereosequences (Table 1, run 1) with one rich in syndiotactic stereosequences (Table 1, run 6). The ${ }^{1} \mathrm{H}$ NMR spectrum of the test sample is shown in Figure 6(c). Triad tacticity cannot be determined by conventional methods such as the integration of isolated peaks. PLS regression was conducted to predict the triad tacticity of the test 


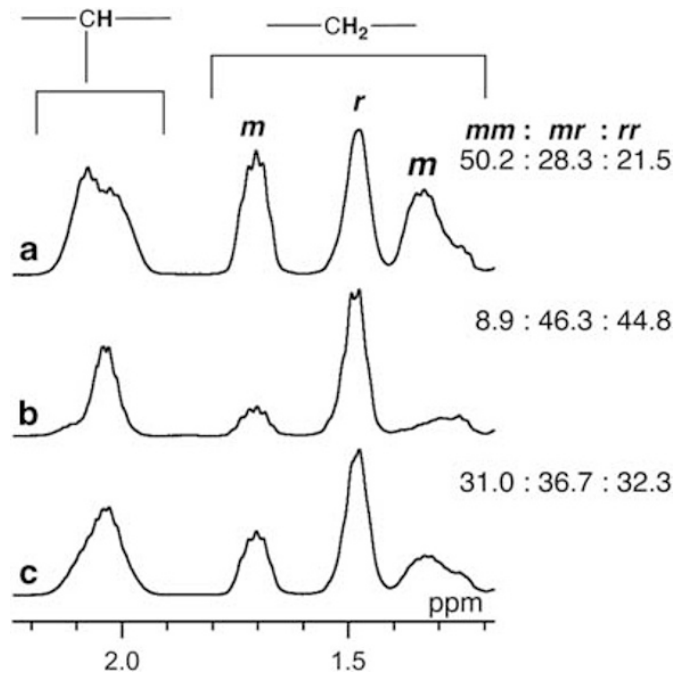

Figure $6{ }^{1} \mathrm{H}$ NMR spectra of original poly(NIPAAm)s rich in (a) isotactic stereosequences (Table 1 , run 1 ) and (b) syndiotactic stereosequences (Table 1, run 6) and (c) that of the test sample prepared by mixing the original polymers. The triad tacticity for (c) was calculated based on the weight fractions of the original polymers, (a) and (b).

sample, using the above-mentioned training data set. The triad tacticity of the test sample was predicted to be mm:mr:rr= 32.5:35.2:32.3\%. The predicted tacticities and calculated ones were in agreement within $1.5 \%$ (see Figure 6). We can conclude that the triad tacticity can be predicted from the ${ }^{1} \mathrm{H}$ NMR spectrum of poly(NIPAAm) using a PLS regression method.

\section{CONCLUSIONS}

It was found that PCA-loadings plots satisfactorily explained the assignments of NMR spectra of poly(NIPAAm)s in terms of stereostructures. Furthermore, triad tacticities were successfully predicted by PLS regression of the ${ }^{1} \mathrm{H}$ NMR spectra. These results mean that chemometric approaches are useful for assignment of NMR spectra in terms of stereostructures and prediction of tacticity distributions. At least in the present system, only eight samples with various stereoregularities were sufficient to provide the reasonable results.

Synthetic polymers have distributions in their primary structures such as stereosequences, molecular weights and regioregularities. Furthermore, synthetic copolymers have distributions in chemical compositions and comonomer sequences. In general, the distributions often prevent the detailed characterization of synthetic (co)polymers. In the present method, however, the disadvantage in conventional analytical methods, changes in tacticity distributions, was used in chemometric analysis of NMR spectra of poly(NIPAAm)s. It is assumed that the present method is a promising method for the characterization of synthetic (co)polymers.

One of the conventional methods of assigning NMR signals of polymers, in terms of stereostructures, is the multipulse-based $2 \mathrm{D}$ NMR method. However, not only the short relaxation times of polymer samples, but also the reduced signal/noise ratios, as a result of splitting caused by stereosequences, have made it difficult to measure conventional multipulse-based 2D NMR spectra of synthetic polymers. Moreover, some 2D NMR techniques, such as HETECOR, favor the use of isotope-labeled samples. ${ }^{24}$ The present method provides correlations between the methine carbons and the methylene protons of unlabeled poly(NIPAAm)s. The correlations correspond to information given by HETECOR and HMBC experiments. Furthermore, it was noteworthy that correlations between the methine carbons, measured in a mixed solvent at $100^{\circ} \mathrm{C}$, and the methylene protons, measured in DMSO- $d_{6}$ at $150{ }^{\circ} \mathrm{C}$, were observed. It is impossible to obtain such correlations by conventional multipulse-based 2D NMR techniques. Consequently, it is assumed that the present method is promising for the characterization of synthetic polymers, in addition to conventional 2D NMR.

\section{ACKNOWLEDGEMENTS}

This work was supported in part by KAKENHI (a Grant-in-Aid for Young Scientists (B) (23750130)).

1 Bovey, F. A. High Resolution NMR of Macromolecules (Academic Press, New York, 1972).

2 Hatada, K., Kitayama, T. \& Ute, K. in Annual Reports on NMR Spectroscopy (ed. Webb, G. A.) Vol. 26, 99-210 (Academic Press, London, 1993).

3 Hatada, K. \& Kitayama, T. NMR Spectroscopy of Polymers (Springer-Verlag, Berlin, 2004).

4 Matsuzaki, K., Uryu, T. \& Asakura, T. NMR Spectroscopy and Stereoregularity of Polymers (Japan Scientific Societies Press, Tokyo, 1996).

5 Bovey, F. A. \& Tiers, G. V. D. Polymer NSR spectroscopy. II. The high resolution spectra of methyl methacrylate polymers prepared with free radical and anionic initiators J. Polym. Sci. 44, 173-182 (1960).

6 Nishioka, A., Watanabe, H., Yamaguchi, I. \& Shimizu, H. High resolution NMR spectra of isotactic and syndiotactic polymethyl methacrylate in chloroform solution. J. Polym. Sci. 45, 232-234 (1960).

7 Johnsen, U. \& Tessmar, K. Hochaufgelöste Kernresonanzspektren von eutaktischen Polymethylmethacrylaten. Kolloid-Z 168, 160-161 (1960).

8 Hirano, T., Okumura, Y., Kitajima, H., Seno, M. \& Sato, T. Dual roles of alkyl alcohols as syndiotactic-specificity inducers and accelerators in the radical polymerization of $\mathrm{N}$-isopropylacrylamide and some properties of syndiotactic poly $(\mathrm{N}$-isopropylacrylamide). J. Polym. Sci., Part A: Polym. Chem. 44, 4450-4460 (2006).

9 Hirano, T., Kamikubo, T., Fujioka, Y. \& Sato, T. Hydrogen-bond-assisted syndiotacticspecific radical polymerization of $\mathrm{N}$-isopropylacrylamide: the solvent effect on the stereospecificity. Eur. Polym. J. 44, 1053-1059 (2008).

10 Hirano, T., Kamikubo, T., Okumura, Y., Bando, Y., Yamaoka, R., Mori, T. \& Ute, K. Heterotactic-specific radical polymerization of $n$-isopropylacrylamide and phase transition behavior of aqueous solution of heterotactic poly( $\mathrm{N}$-isopropylacrylamide). J. Polym. Sci., Part A: Polym. Chem. 47, 2539-2550 (2009).

11 Hirano, T., Morikami, A., Fujioka, Y. \& Ute, K. Effect of a combination of hexamethylphosphoramide and alkyl alcohol on the stereospecificity of radical polymerization of $\mathrm{N}$-isopropylacrylamide. Polymer 52, 629-634 (2011).

12 Isobe, Y., Fujioka, D., Habaue, S. \& Okamoto, Y. Efficient Lewis acid-catalyzed stereocontrolled radical polymerization of acrylamides. J. Am. Chem. Soc. 123, 7180-7181 (2001).

13 Okamoto, Y., Habaue, S., Isobe, Y. \& Suito, Y. Stereocontrol using Lewis acids in radical polymerization. Macromol. Symp. 195, 75-80 (2003).

14 Kitayama, T., Shibuya, W. \& Katsukawa, K-i. Synthesis of highly isotactic poly ( $\mathrm{N}$-isopropylacrylamide) by anionic polymerization of a protected monomer. Polym. J. 34, 405 (2002)

15 Ito, M. \& Ishizone, T. Living anionic polymerization of $\mathrm{N}$-methoxymethyl- $\mathrm{N}$-isopropylacrylamide: synthesis of well-defined poly( $N$-isopropylacrylamide) having various stereoregularity. J. Polym. Sci., Part A: Polym. Chem. 44, 4832-4845 (2006).

16 Hirano, T., Kamikubo, T., Okumura, Y. \& Sato, T. Heterotactic poly ( $\mathrm{N}$-isopropylacrylamide) prepared via radical polymerization in the presence of fluorinated alcohols. Polymer 48, 4921-4925 (2007).

17 Everall, N., Tayler, P., Chalmers, J. M., MacKerron, D., Ferwerda, R. \& van der Maas, J. $\mathrm{H}$. Study of density and orientation in poly(ethylene terephthalate) using Fourier transform Raman spectroscopy and multivariate data analysis. Polymer 35, 3184-3192 (1994).

18 Shimoyama, M., Maeda, H., Matsukawa, K., Inoue, H., Ninomiya, T. \& Ozaki, $Y$. Discrimination of ethylene/vinyl acetate copolymers with different composition and prediction of the vinyl acetate content in the copolymers using Fourier-transform Raman spectroscopy and multivariate data analysis. Vib. Spectrosc. 14, 253-259 (1997).

19 Sato, H., Shimoyama, M., Kamiya, T., Amari, T., Šašic, S., Ninomiya, T., Siesler, H. W. \& Ozaki, Y. Raman spectra of high-density, low-density, and linear low-density polyethylene pellets and prediction of their physical properties by multivariate data analysis. J. Appl. Polym. Sci. 86, 443-448 (2002).

20 Sellers, K. W., Towns, C. M., Mubarak, C. R., Kloppenburg, L., Bunz, U. H. F. \& Morgan, S. L. Characterization of high molecular weight poly(p-phenylenethynylene)s by pyrolysis gas chromatography/mass spectrometry with multivariate data analysis. J. Anal. Appl. Pyrolysis. 64, 313-326 (2002). 
21 Hughes, J., Shanks, R. \& Cerezo, F. Characterisation of the comonomer composition and distribution of copolymers using chemometric techniques. J. Therm. Anal. Calorim. 76, 1069-1078 (2004).

22 Marengo, E., Longo, V., Bobba, M., Robotti, E., Zerbinati, O. \& Di Martino, S. Butene concentration prediction in ethylene/propylene/1-butene terpolymers by FT-IR spectroscopy through multivariate statistical analysis and artificial neural networks. Talanta 77, 1111-1119 (2009).
23 Momose, H., Hattori, K., Hirano, T. \& Ute, K. Multivariate analysis of ${ }^{13} \mathrm{C}$ NMR spectra of methacrylate copolymers and homopolymer blends. Polymer 50, 3819-3821 (2009).

24 Moad, G., Rizzardo, E., Solomon, D. H., Johns, S. R. \& Willing, R. I ${ }^{13} \mathrm{C}-{ }^{1} \mathrm{H}$ heteronuclear chemical shift correlation spectroscopy applied to poly(methyl [carbo$\left.n y /{ }^{13} \mathrm{C}\right]$ methacrylate): an unambiguous method for assigning resonances to configurational sequences. Macromolecules 19, 2494-2497 (1986). 